\title{
Vingar e punir: motivações para a prática do spoiling
}

\section{Avenge and punish: motivations for spoiling}

Melina Meimaridis ${ }^{1}$

Thaiane Oliveira ${ }^{2}$

Resumo: Através de um survey com fãs brasileiros de séries televisivas americanas $(n=1.805)$, buscamos lançar luz sobre a prática do spoiling. Sabendo que a prática realizada pelos fãs é constituída por discursos enraizados no capital cultural e subcultural e, em negociações de poder dentro de cada comunidade, procuramos entender o espectro de toxicidade por trás do spoiling. Os resultados indicam que o spoiling tornou-se uma fonte de sociabilidade, troca de conhecimento, bem como prazer para o fã brasileiro. Porém, a prática também é utilizada por vingança ou até mesmo para "punir" espectadores atrasados. Observou-se que os fãs se aproveitam da possibilidade de mostrar mais conhecimento entre si, levando a conflitos nos fandoms e revelando o potencial tóxico por trás da difusão de spoilers.

Palavras-chave: spoiling; séries; fãs; práticas tóxicas.

Abstract: Through a survey with Brazilian fans of American television series $(n=1,805)$, we seek to shed some light on the practice of spoiling. Having in mind that fans' spoiling practices are made up of discourses rooted in cultural capital or subcultural capital, and in the dynamics of power inside communities, we seek to understand the spectrum of toxicity behind the practice of spoiling. The results indicate that spoiling has become a source of sociability, knowledge exchange, as well as, pleasure. However, the practice is also used for vengeance

1 Universidade Federal Fluminense (UFF). Niterói, RJ, Brasil. https://orcid.org/0000-0003-3481-817X E-mail: melmaridis@hotmail.com 2 Universidade Federal Fluminense (UFF). Niterói, RJ, Brasil. https://orcid.org/0000-0002-8588-3548 E-mail: thaianeoliveira@id.uff.br 
510 VINGAR E PUNIR

and to "punish" tardy viewers. It was observed that fans take advantage of showing more knowledge among each other, culminating in conflict in the fandoms and revealing the toxic potential behind the circulation of spoilers.

Keywords: spoiling; series; fans; toxic practices. 


\section{Introdução}

No atual contexto midiático, spoilers têm se tornado uma questão relevante para fãs e consumidores de narrativas audiovisuais, especificamente de séries televisivas. De modo simples, spoilers são definidos como uma "informação que adianta um final ou um ponto importante" de uma narrativa (PASE; SACCOMORI, 2015, p. 189). Embora o assunto tenha sido abordado por alguns estudos (GRAY; MITTELL, 2007; PERKS; MCELRATH-HART, 2016a), a maior parte da literatura reflete um foco na dimensão da recepção e no consumo desse paratexto. Entretanto, neste trabalho optamos por focar nossa análise em uma face ainda pouco explorada do problema: a questão da prática do spoiling, ou seja, a produção e circulação de spoilers.

A preponderância de estudos acadêmicos na dimensão da recepção de spoilers está relacionada ao fato de que é culturalmente aceito que o consumo desse paratexto pode prejudicar a experiência do consumo do texto, principalmente, porque essa ação acarreta em uma quebra da expectativa e do suspense (JOHNSON; ROSENBAUM, 2015). Recentemente, essa visão negativa tem sido questionada por alguns autores que propõem a possibilidade de um engajamento positivo com spoilers (GRAY; MITTELL, 2007; HASSOUN, 2013).

Ao mesmo tempo, a questão tornou-se mais complexa com o surgimento das redes sociais que permitem que os fãs se agrupem coletivamente e compartilhem informações on-line sem restrições ou limitações. A falta de identificação de postagens com spoilers no Facebook e no Twitter altera a dinâmica em torno da discussão de maneira que estudos anteriores talvez não tenham sido capazes de resolver. Porque os fandoms comumente operam nessas redes sociais, a dicotomia entre pessoas que amam ou odeiam spoilers se torna extremamente problemática ao unir em uma mesma comunidade on-line esses indivíduos, criando, assim, um espaço de disputas e contendas entre as duas visões. A situação se torna muito intrigante quando se entende que uma parte do prazer de se consumir uma narrativa televisiva se encontra no diálogo entre os fãs e outros espectadores sobre essas produções (BAYM, 2000). 
Reconhecendo que a prática do spoiling é tão importante quanto a recepção do paratexto, realizamos uma pesquisa com os fãs brasileiros de séries televisivas americanas $(\mathrm{n}=1.805)$ através de um survey disponibilizado em 10 grupos de Facebook. As séries americanas têm se popularizado no Brasil na última década apesar das dificuldades que certos indivíduos encontram de obter acesso a essas narrativas. Muitos fãs ainda dependem de links piratas e esperaram dias para conseguirem legendas em português. Nesse contexto, observa-se que os brasileiros são o $4^{\circ}$ maior número de usuários de internet ${ }^{3}$ e são o $6^{\circ}$ maior número de usuários do Twitter ${ }^{4}$. Esse aumento do interesse pelas séries americanas e a forte presença on-line permite que os brasileiros sejam expostos a spoilers, em suas redes sociais, vindo de fãs americanos e até mesmo de outros fãs brasileiros que consomem essas narrativas através de links piratas ao vivo, dessa forma gerando incontáveis conflitos.

Tendo em vista que as práticas de spoiling dos fãs são constituídas de discursos enraizados no capital cultural, capital subcultural (THORNTON, 1995; CASTELLANO et al., 2017) e nas dinâmicas de poder dentro das comunidades de fãs (WILLIAMS, 2004), buscamos entender o espectro de toxicidade da prática do spoiling. Os resultados indicam que, embora uma grande maioria afirme só fornecer spoilers quando o paratexto é solicitado, uma parcela relativamente significativa aproveita a possibilidade de mostrar mais conhecimento entre si. Portanto, o spoiler pode ser configurado como um mecanismo usado na luta pelo poder, bem como, capital social e subcultural em fandoms de séries. Ao mesmo tempo, entendemos que, devido à interpretação cultural particular que os brasileiros possuem da prática, eles se aproveitam para fornecerem spoilers afetando a experiência de outro indivíduo para seu próprio prazer pessoal ou mesmo para revelar o acesso a um bem material, a TV paga.

3 https://goo.gl/FWhVy6

4 https://goo.gl/TMJ4DT 


\section{Spoilers: definição, recepção e função}

Apesar de serem culturalmente aceitos como paratextos que prejudicam o consumo de uma narrativa, os spoilers ainda são pouco estudados na literatura acadêmica, sendo que a maior parte dos estudos existentes enfatizam análises empíricas que possuem resultados inconclusivos ou discordantes. A dificuldade de se estudar spoilers ocorre por diversos fatores, dentre os quais o surgimento de tecnologias de time shifting (GRAY, 2010), a distribuição assíncrona de conteúdo (NEWMAN, 2011), e os avanços tecnológicos da última década que permitiram aos espectadores a oportunidade de (re)ver programas após seus términos (PERKS; MCELRATH-HART, 2016a). Para melhor abordar o assunto lançaremos luz sobre três principais pontos que consideramos importantes para se compreender a complexidade do tema: definição, recepção e função.

Spoilers são um tipo particular de paratexto que não possuem uma definição claramente estabelecida. Gray e Mittell (2007, p. 2) argumentam que a definição é muito variável de pessoa para pessoa. Existiriam aqueles que acreditam que qualquer informação seria um spoiler, ao passo que para outros spoilers seriam apenas informações importantes dos desenlaces narrativos. Paralelamente, existe uma multiplicidade de definições na Academia. Perks e McElrath-Hart (2016a) apontam que por muitos anos pesquisadores possuíam uma perspectiva de que spoilers seriam apenas informações relevantes divulgadas antes da exibição da série. Com isso em mente, após a exibição do episódio essas informações deixariam de ser spoilers. Com o surgimento de novas tecnologias e a popularização das práticas de time shifting essa visão se tornou obsoleta, visto que as narrativas podem ser consumidas dias, semanas, meses e até anos após a exibição.

Em segundo lugar, observamos que a literatura tem se concentrado demasiadamente na recepção do paratexto e nas consequências de seu consumo para o aproveitamento de uma narrativa (BAYM, 2000; JOHNSON; ROSENBAUM, 2015). Recentemente, através de uma perspectiva multidimensional, pesquisadores têm argumentado que spoilers podem ser consumidos voluntariamente e que seu consumo 
pode até ser prazeroso (GRAY; MITTELL, 2007; HASSOUN, 2013). Perks e McElrath-Hart (2016a) vão além ao apontarem a existência de certa ambivalência em relação ao consumo de spoilers. Para as autoras, quanto maior o investimento de um espectador com uma narrativa, maior o seu desejo de evitar spoilers. Assim, um único espectador pode receber o paratexto de forma favorável e desfavorável dependendo do seu investimento em uma dada narrativa. Alternativamente, no estudo empírico realizado por Gray e Mittell (2007), os autores propõem que a busca por spoilers nasce pelo aumento do interesse do espectador pela série, no caso, o drama Lost (ABC, 2004-2010). A aparente contradição entre os dois estudos revela a complexidade e ambivalência por trás da recepção de spoilers.

Por fim, é preciso considerar que spoilers possuem diferentes funções. Hassoun (2013), ao analisar o consumo desse paratexto, argumenta que eles podem saciar a curiosidade de fãs e intensificar a ansiedade. Já Gray e Mittell (2007) identificam uma função preparatória visto que ao consumir um spoiler espectadores de Lost alegavam que podiam prestar mais atenção durante a exibição do episódio, já que a suspensão do choque lhes permitia maior concentração aos detalhes que estavam transcorrendo no episódio. Semelhantemente, Williams (2004, p. 7) encontrou uma motivação preparatória distinta por parte dos fãs de Buffy the Vampire Slayer (WB, 1997-2001/UPN, 2001-2003) que consumiam spoilers como forma de se preparar emocionalmente para os acontecimentos futuros da série, como, por exemplo, a morte de um personagem.

Tendo em vista esse breve panorama e entendendo que a maior parte das análises focadas no paratexto e em sua recepção se contradiz, entendemos que a discussão acadêmica em torno da questão tem que buscar novos caminhos analíticos, não podendo continuar limitada ao paratexto, enquanto a esfera da difusão e circulação de spoilers continuam relativamente menosprezadas. 


\section{Spoiling, poder e disputas}

Este trabalho aborda um grupo específico em sua análise: os fãs brasileiros de séries americanas. Os critérios que definem o fã ainda variam um tanto na literatura acadêmica. Nesse trabalho partimos do princípio de que os fãs se distinguem da audiência geral por conta do seu relacionamento particular com uma dada obra, marcado por uma admiração pelo texto e envolvimento com ele através das mais variadas práticas. Jenkins propõe a seguinte definição:

Alguém se torna um 'fã' não por ser um espectador regular de um determinado programa, mas por traduzir aquela experiência em algum tipo de atividade cultural, compartilhando sentimentos e pensamentos sobre o conteúdo do programa com os amigos, juntando-se a uma "comunidade" de outros fãs que compartilham interesses comuns. (2006a, p. 4l, tradução nossa)

No Brasil a área de estudos de fãs conta com muitos trabalhos de qualidade que abordam temas que se aproximam com as discussões apresentadas neste artigo (CAMPANELLA, 2012; CASTRO, 2012; FECHINE, 2015). Alguns trabalhos buscam apresentar e discutir as práticas de fãs no contexto da cultura digital (AMARAL; SOUZA; MONTEIRO, 2015). Dentre as práticas que normalmente recebem atenção, como por exemplo, fanfics, fanarts e, inclusive ativismo fã, a prática do spoiling entre fãs ainda permanece pouco explorada.

Para entender as motivações que os fãs têm para realizarem o spoiling é importante compreender que se os spoilers possuem qualidade e significado inerentes individuais (HILLS, 2012), fãs brasileiros podem ter uma interpretação diferente da prática, portanto possuindo motivações distintas. No Brasil e em outros países é comum se deparar com a questão da disparidade temporal como a principal motivação por trás do spoiling entre fãs, visto que a difusão de spoilers sempre foi motivada por questões temporais (JENKINS, 2009). Atualmente, ao passo em que o compartilhamento de arquivos on-line no modelo "peer-to-peer" (P2P) tem "resolvido alguns dos problemas" temporais relacionados à 
distribuição assíncrona de conteúdo global (NEWMAN, 2012, p. 465), essa prática tem acalentado o debate acerca do spoiling ao redor do mundo.

No caso brasileiro, observa-se que por muitos anos os indivíduos dependiam da assinatura da TV paga ou da "boa vontade" das emissoras abertas, que exibiam as séries muitas vezes incompletas, para consumirem séries estrangeiras. Apesar da popularização da televisão a cabo no Brasil, observa-se que esta ainda chega a uma quantidade relativamente pequena da população (LÓPES; GÓMEZ, 2017). Assim, fãs brasileiros muitas vezes dependem de downloads piratas ou do acesso a serviços de streaming, como a Netflix, para consumirem suas séries. Paralelamente, observa-se que devido ao fato de que apenas uma quantidade limitada da população tem acesso à televisão por assinatura, essas produções ganharam certo status e prestígio no país. Isso é relevante porque influenciará o relacionamento particular que os brasileiros têm com spoilers e na forma como eles interpretam e traduzem a prática do spoiling, como argumentaremos mais a frente.

Embora a justificativa da disparidade temporal seja plausível não podemos considerála a única resposta para essa questão. É necessário entender que as práticas na cultura digital são entidades coordenadas que convocam as performances e estas podem ser as mesmas ou não a partir de uma mesma prática de apropriação (WARDE, 2005). Utilizando a Teoria de Prática, Sandra Montardo (2016) defende que há a necessidade de se definir e diferenciar consumo de prática na cultura digital. Para ela, é possível entender "o consumo como fator de performance na prática da socialização online, de modo que consumo, nesse sentido, consiste no acesso, na produção, na disponibilização e no compartilhamento de conteúdo digital" (MONTARDO, 2016, p. 14). Nesta perspectiva, o consumo é o elemento viabilizador da prática da socialização on-line que se dá dentro das práticas, sendo necessária a aplicação de conhecimentos por parte de quem as pratica, inferindo sobre a percepção de capital social sobre eles (RECUERO, 2009). 
Com isto posto, observamos que na "economia informacional da internet, conhecimento é igual a prestígio, reputação e poder [...] então existe uma compulsão por ser o primeiro a circular novas informações e ser o primeiro a possuílla" (JENKINS, 2006b, p. 125, tradução nossa). Apesar das dificuldades em se definir spoilers, é incontroverso pensar em spoilers como informações acerca de um determinado texto. Tendo em vista que o "controle do conhecimento é uma das principais formas de poder social" (BROWN, 1994, p. 132, tradução nossa), pode-se afirmar que o acúmulo de informação através do consumo de spoilers demonstra uma concentração de conhecimento que proporciona ao indivíduo maior capital subcultural dentro de um determinado fandom.

O termo capital subcultural foi cunhado por Sarah Thornton (1995) e se aproxima da noção de capital cultural teorizada por Bourdieu (1989). Enquanto o capital cultural é acumulado através da concentração de conhecimento, o capital subcultural funciona de modo semelhante, entretanto, em vez de ir pelo viés da erudição, o indivíduo que acumula esse capital possui um conhecimento valorizado por uma determinada subcultura. Assim, no caso das comunidades de fãs de ficção seriada televisiva, os indivíduos podem se aproveitar para demonstrar capital subcultural e acumular poder sobre os fãs menos conhecedores através do compartilhamento de spoilers (WILLIAMS, 2004).

Nesse mesmo seguimento, quando o fã publica spoilers na comunidade ele adquire poder, visto que ele se torna uma fonte de informações. Para Williams (2004, p. 8) os fãs conhecedores de spoilers de Buffy eram considerados mais "bem-informados" (knowledgeable) do que os fãs que não consumiam e/ou divulgavam spoilers. Assim, o autor estabelece que informação $=$ controle $=$ poder. Alternativamente, Perks e McElrath-Hart argumentam que no atual contexto televisivo o isolamento também é uma forma de controle conversacional e, portanto, poder (2016a, p. 6-7). Assim, as autoras argumentam que muitos espectadores são assertivos sobre a quantidade de informações a que eles querem ter acesso e lutam pelo estabelecimento de normas e éticas que os protejam dos spoilers. 
Considerando que a disparidade temporal e a disputa por poder são apenas algumas das possíveis razões para o spoiling e tendo em mente o uso específico que os brasileiros fazem da prática, buscamos problematizar a questão e investigar a existência de outras motivações por trás da prática.

\section{Metodología}

Para a realização deste trabalho, foi elaborado um survey com 23 perguntas abertas e fechadas, distribuído em 10 grupos $^{5}$ de fãs de séries no Facebook de diferentes formatos e gêneros, buscando atingir um público amplo e obter maior grau de variabilidade da amostra. É importante ressaltar que optamos por não restringir a análise a um determinado grupo de fãs, mas, sim, realizamos um estudo com um grupo abrangente de consumidores e espectadores ávidos de séries televisivas, pois acreditamos que determinadas produções podem conduzir seus fãs a se relacionarem de formas distintas com os spoilers. Ao total, foram coletadas 1.805 respostas validadas. O survey recebeu respostas ao longo de 10 dias entre 30 de abril e 10 de maio de 2016. As perguntas foram divididas em: i) perfil do respondente, ii) consumo de spoilers voluntários, iii) consumo involuntário de spoilers e iv) produção de spoilers ${ }^{6}$. Nesta amostra total, 71,6\% ( $\mathrm{n}=1.293)$ são do gênero feminino, $28 \%(\mathrm{n}=506)$ masculino e $0,3 \%$ ( $n=06)$ não binários. A idade mínima dentre os respondentes foi 11 anos e a máxima 62 anos. Sobre o consumo de séries, a maior parte $(41,7 \%)$ assiste até cinco produções seriadas atualmente e dedica-se entre uma a duas horas ao consumo de séries por dia $(36,5 \%)$.

A partir disso, foi realizado um recorte sobre os respondentes que disseram que costumam dar spoilers, questão central para a discussão deste trabalho, totalizando $787(\mathrm{n}=787)$ respondentes, representando 43,6\% do total de respostas coletadas. Nesta amostra, foi realizada categorização

5 O questionário foi divulgado nos seguintes grupos do Facebook: Grey's Anatomy You're My Person; Viciados em Séries e Sagas; How I Met Your Mother Brasil; Glee Brasil; Game of Thrones da Depressão; Game of Thrones Brasil L\&S; The Big Bang Theory Brasil; Netflix Brasil Assinantes; Netflix Brasil - Assinantes; Séries da Depressão.

6 Para este trabalho, nós focaremos apenas na questão sobre a produção de spoiler. 
lexical e semântica para análise de conteúdo (BARDIN, 2011), a partir do tipo de resposta dada foram indicadas sete categorias amplas, divididas em "Práticas não tóxicas": Acidental (26,3\%), Politicamente correto $(37,9 \%)$, Sociabilidade (23,8\%), Informativo $(8,76 \%)$, e Outros $(4,06 \%)$, e "Práticas Tóxicas": Prazer (17,9\%) e Vingança (5,46\%). Deve se observar que como as perguntas eram abertas, algumas respostas podiam ser enquadradas em duas ou mais categorias, como, por exemplo, a resposta de Paula7: "Às vezes é involuntário, às vezes de sacanagem e às vezes porque a pessoa pede" (mulher, 29 anos).

\section{Discussão/Análise dos resultados}

A palavra “tóxico" vem da expressão desenvolvida por John Suler (2004), na qual ele descreve diferentes efeitos de desinibição no ambiente on-line. Segundo Suler, o anonimato, a invisibilidade, a assincronia, a introjeção e a diminuição da autoridade são elementos que afetam um comportamento desinibido em ambientes on-line, de ambas as formas: positivamente, um comportamento benigno baseado em atos de bondade e generosidade; e negativamente, como um comportamento tóxico de práticas interativas. Conforme indicado pelo psicólogo, o comportamento tóxico em ambientes on-line pode ser entendido como um ato catártico de prazer motivado por necessidades e desejos desagradáveis sem qualquer crescimento pessoal.

Embora discutamos que a desinibição não é o único elemento que fornece comportamentos tóxicos em ambientes on-line, como mostraremos durante a análise, dividimos os dados em duas categorias com base na definição de Suler: Práticas não tóxicas - entendidas por nós como qualquer atividade na qual não há intenção de gerar conflitos em uma relação interpessoal e/ou dentro de uma determinada comunidade, especificamente, a circulação não intencional de spoilers e/ou a circulação de spoilers desejados - e Práticas tóxicas - entendidas aqui como qualquer atividade que intencionalmente leve a conflitos dentro de uma

7 Todos os respondentes receberam pseudônimos. Incluímos o gênero e a idade para refinar quaisquer padrões relacionados à condição do sujeito. 
relação interpessoal e/ou uma comunidade particular, especificamente, a circulação intencional de spoilers indesejados.

\section{Práticas não tóxicas}

\section{Acidental}

Muitos respondentes ( $\mathrm{n}=207$ ) apontaram que forneciam spoilers "sem querer" ou "de forma não intencional" como pode ser observado na resposta da Rebecca: "Normalmente é sem querer, acidente" (mulher, 23 anos); ou da Bárbara: "É raro acontecer e geralmente não é intencional, acontece por eu achar que a pessoa já assistiu tal episódio" (mulher, 20 anos). Há também os indivíduos que alegam não estarem prestando atenção e acabam soltando um spoiler como na fala de João: "Desatenção" (homem, 21 anos). Observa-se que alguns respondentes apontaram a existência de um "prazo de validade" para os spoilers, qualidade já indicada no trabalho de Castellano et al., (2017), como, por exemplo, a resposta de Thaís: "Eles escapam. Mas às vezes eu presumo que a pessoa viu algo de cinco anos atrás e ela não viu” (mulher, 26 anos).

\section{Politicamente correto}

A categoria com o maior número de respostas foi a do politicamente correto $(n=299)$ em que os respondentes indicavam fornecer spoilers somente quando alguém os solicitava, como pode ser evidenciado na resposta de Daniel: "Quando pedem somente" (homem, 28 anos); ou na de Alessandra: "Porque as pessoas pedem. Não daria spoiler sem o consentimento do outro" (mulher, 26 anos). Em alguns casos os respondentes reafirmam seus status de "mais bem-informados" (knowledgeable) como na fala de Daniela: "Como sei muito sobre as séries, as pessoas me perguntam" (mulher, 30 anos), indicando a existência de uma disputa sobre informação em torno do capital subcultural (THORNTON, 1995) presente entre os fãs de séries, a ser analisado em trabalhos futuros. 


\section{Sociabilidade}

A categoria da sociabilidade engloba as respostas $(n=188)$ que indicaram a necessidade/ansiedade de se falar sobre os acontecimentos de uma determinada série como na fala de Alex: "Pela ansiedade que há em comentar algum evento ocorrido em uma série” (homem, 26 anos). Muitos indicaram uma "empolgação" e uma dificuldade de se abster como na resposta de Simone: "Gosto de compartilhar minha felicidade em relação a algo que aconteceu. Quando é algo ruim, quero ver se a pessoa teria a mesma reação que eu de indignação. Eu me esforço ao máximo para não dar, mas, às vezes, eu falo tão empolgada que alguns amigos acabam cedendo" (mulher, 19 anos). Com isso, Simone indica a necessidade de ter uma plateia ou uma válvula de escape para seus pensamentos sobre o programa que está consumindo.

Ao mesmo tempo, alguns respondentes ressaltaram que a troca de spoilers ocorreria, pois eles tinham a necessidade de conversar sobre a série, trocando hipóteses, ideias e suposições do que viria a acontecer na produção, como na fala de Beatriz: "Forneço spoilers a quem se propõe a ouvir. Ou seja, forneço para fins de discussão e formulação de hipóteses acerca das situações" (mulher, 22 anos). Em outros casos os respondentes alegaram que spoilers fazem parte da conversa sobre ficção seriada televisiva como na fala de Luiza: "Pois quero conversar sobre a série e não dá pra discutir certos assuntos sobre as mesmas sem fornecer spoilers" (mulher, 20 anos).

A necessidade de uma plateia pode, às vezes, levar um fã a medidas mais extremas, com os entrevistados indicando que às vezes eles ameaçam seus amigos e conhecidos com spoilers para que eles não "fiquem atrasados" e consumam a série no mesmo ritmo, como pode ser observado na afirmação de Afonso: "Mais ameaço do que falo, com o intuito de que os amigos assistam logo para podermos conversar sobre a série" (homem, 24 anos); e de Denis: "Brincadeira, quem sabe desse jeito a pessoa assiste no dia e fica atualizada, dessa forma podemos conversar sobre todo o episódio" (homem, 16 anos). Essas "ameaças" novamente trazem à tona a questão da sociabilidade, invariavelmente, associada 
com o consumo televisivo. Entretanto, aqui, um fã se aproveita de possuir "mais conhecimento" do que o outro e faz uma "chantagem" para que este acompanhe a série em seu ritmo. A informação presente entre este grupo integra um emaranhado de relações de poder no qual atuam diferentes sujeitos, a partir de distintas dinâmicas sociais, para os quais os processos de negociação de informação têm algum tipo de valor e de interesse, sobretudo social. Mais do que querer ser um dos primeiros a circular a informação, tal como apontado por Jenkins (2006b), o spoiler também é visto como um mecanismo de sociabilidade construído em dinâmicas próprias para além do prestígio entre seu grupo social.

\section{Informativo}

A categoria "Informativo" ( $n=69)$ abarca as respostas que indicaram na prática do spoiling a funcionalidade de informar e transmitir informação sobre alguma determinada produção para outros indivíduos, como pode ser observado na fala de Tiago: "Eu normalmente dou spoiler sobre algum acontecimento da série para aumentar a curiosidade da pessoa sobre a série. No meu círculo de amizade isto é algo comum, sempre que recomendamos uma série para os outros nós compartilhamos um spoiler" (homem, 19 anos); e Eduarda: "Necessidade de repassar informação" (mulher, 23 anos). Ao mesmo tempo, muitos dos respondentes indicaram fornecer spoilers como forma de "atiçar" a curiosidade de seus amigos, incentivando-os a começarem ou continuarem a assistir alguma série, como indicado por Bruno: "Instigar a pessoa a assistir aos próximos capítulos” (homem, 21 anos).

\section{Outros}

A categoria "Outros" $(\mathrm{n}=32)$ comporta um pequeno percentual $(4,06 \%)$ das respostas que em linhas gerais foram indivíduos que não sabiam exatamente porque produziam spoilers como pode se observar na resposta de Lígia: "Por que, não sei" (mulher, 28 anos). Por outro lado, Davi indicou soltar "fake spoilers" ou spoilers falsos para a "pessoa 
ficar chateada e na hora ficar surpreendida!” (homem, 18 anos). Porém, outros respondentes afirmaram não se importar com o paratexto e, por este motivo, assumirem que outros também não se importam como na fala de Pedro: "Geralmente as pessoas não se importam tanto com isso, assim como eu, então não faço questão de dar assim como não faço questão de não dar" (homem, 21 anos).

\section{Práticas tóxicas}

\section{Prazer}

Dentre as práticas tóxicas a categoria que recebeu o maior número de respostas foi a do "Prazer" ( $\mathrm{n}=141)$ em que os respondentes apontaram sentimentos de "diversão" e "gozo" na prática do spoiling, como pode ser observado na fala da Raquel: "É engraçado" (mulher, 17 anos); e da Talita: "É legal ver os amigos com raiva” (mulher, 15 anos). Cristal vai um pouco mais a fundo ao afirmar que: "Porque é bom ver o sofrimento das pessoas!!" (mulher, 16 anos). Similarmente, alguns respondentes indicaram ser prazeroso frustrar a experiência do outro, como Ana: "Porque é uma sensação boa tirar o prazer da pessoa de se surpreender com aquilo enquanto assiste" (mulher, 15 anos); Isabella: "Para estragar a expectativa do colega" (mulher, 37 anos). Como podemos ver, não é um comportamento instigado pela desinibição ou anonimato, como apresentado por John Suler (2004) ao analisar a dinâmica psicológica no ciberespaço, mas uma prática que reforça a distinção de possuir conhecimento entre pares através do prazer. Demonstrando que esse prazer é tanto um fenômeno psicológico quanto uma prática sensível ao contexto subjugada a um comportamento cultural do povo brasileiro, alguns dos respondentes usaram a expressão brasileira 'zoeira', pois eles praticariam o spoiling apenas para se divertir com seus amigos.

A noção de prazer atrelada a um maior conhecimento de um fã pode ser observada na fala de Gustavo: "É prazeroso mostrar que vc tem informações que o outro fã ainda não sabe” (homem, 33 anos). $O$ fato da TV por assinatura no Brasil ainda ser restrita a uma pequena parcela da 
população que pode pagar por ela, contribui para o pensamento de que quem tem acesso a esse conteúdo teria "mais direitos" do que os outros fãs, como pode ser evidenciado na resposta de Thales: "Para enaltecer meu ego, e mostrar aos meus amigos pobres que tenho TV por assinatura com canais premium" (homem, 19 anos). O jovem certamente busca se distinguir de seus amigos por ter acesso a este serviço no Brasil, tratando-se de distinções que não se atêm apenas ao capital econômico, mas a um espaço multidimensional no qual diferentes formas de capital (social, econômico, simbólico...) se manifestam pela reafirmação social de apropriação de diferentes bens. Conforme aponta Bourdieu:

O mundo social pode ser concebido como um espaço multi-dimensional construído empiricamente pela identificação dos principais fatores de diferenciação que são responsáveis por diferenças observadas num dado universo social ou, em outras palavras, pela descoberta dos poderes ou formas de capital que podem vir a atuar, como ases num jogo de cartas neste universo específico que é a luta (ou competição) pela apropriação de bens escassos... (BOURDIEU, 1987. p. 4, tradução nossa)

Apesar de expressarem prazer em revelar spoilers, a fala de Rafael demonstra a reação negativa de seus amigos quando diz: "Gosto de contar para os amigos que não assistiram ainda, só pra ver eles bravos. Sou xingado muitas vezes" (homem, 30 anos). O que percebemos a partir dessa fala é que as disputas em torno do capital subcultural não se restringem unicamente ao status ou prestígio dentro de um grupo social (BOURDIEU, 1979), mas se referem também a uma dinâmica na qual as distinções hierárquicas se constroem a partir do domínio informacional, independente de ser reconhecido positivamente entre os pares, contrariando todo um viés em que aponta a legitimação do sujeito dentro de um fandom. Portanto, não se trata de uma legitimação entre os sujeitos (BOURDIEU, 1987), mas disputas em torno da informação como um bem valioso e instrumento de poder, corroborando com os trabalhos desenvolvidos por Williams (2004) e Perks e McElrath-Hart (2016a), mencionados anteriormente. 


\section{Vingança}

O que podemos observar é que nas práticas tóxicas - a informação sendo um instrumento de distinção, como frisado anteriormente - dinâmicas sociais são construídas em uma negociação constante entre fandoms, estabelecendo relações políticas entre saberes. A categoria de "Vingança" $(n=43)$ é considerada por nós a que demonstra o maior potencial tóxico da prática do spoiling. Nesta categoria, os respondentes indicaram utilizar o spoiling como forma de se vingarem de outros indivíduos que já soltaram spoilers indesejados no passado, como na fala de Carol: "Eu costumo 'devolver' spoiler pra quem solta um spoiler pra mim quando eu não quero" e de Adriana: "Geralmente como forma de vingança por ter recebido algum outro spoiler anteriormente" (mulher, 20 anos).

Nesse sentido, o spoiling se torna um mecanismo de justiça em que pessoas que foram "injustiçadas" (receberam um spoiler) se sentem no direito de punir outros. Entretanto, essa motivação não se encontra apenas ligada a incidentes prévios com o paratexto, alguns respondentes foram mais longe e afirmaram fornecerem spoilers por outras razões como na fala de Caio: "Geralmente eu repasso o spoiler que recebi ou de algo que já assisti quando a pessoa é muito chata ou não gosto muito dela. Quando sinto raiva de ter visto o spoiler sem querer eu conto pra alguém também, pois assim a raiva será compartilhada (n me julguem obrigada)" (homem, 22 anos). É implícito na resposta do jovem que ele considera suas ações tóxicas, e até mesmo pode se envergonhar delas "não me julguem" -, mas ainda se sente confortável o suficiente para usar spoilers como forma de gerar conflitos nas relações sociais.

A prática do spoiling, dessa forma, é utilizada como um mecanismo social não só de justiça, mas de punição como pode ser notado na fala de Camilla: "Porque às vezes, amiguinhos que não curtem spoilers fazem ou dizem coisas desagradáveis pra gente” (mulher, 26 anos); e Gabriel: "Apenas quando um amigo comete algum tipo de ação que não gosto!" (homem, 16 anos). A fala de Lilian é particularmente elucidativa sobre a forma como a prática do spoiling pode ser usada como mecanismo de vingança e punição: "Vingança. Quando alguém faz isso comigo eu 
apenas retribuo o 'favor'. Ver a expressão na cara da pessoa quando a gente solta um spoiler tipo ‘quem morreu foi o Glenn' não tem preço. Ou quando o namorado faz uma coisa errada, às vezes nem vale a pena brigar, eu só solto um spoiler enorme de GoT e pronto" (mulher, 24 anos). Através da citação de Lilian, também podemos observar que a posse de conhecimento não é apenas um elemento importante do capital social, mas é usado como uma moeda de barganha na categoria de vingança. Essa negociação não se restringe apenas à dinâmica do consumo da produção audiovisual, mas pode servir para outras disputas diárias. Também podemos ver a representação cultural de comportamentos tóxicos como parte da identidade cultural brasileira, refletida na resposta de Rodrigo quando ele usa sua nacionalidade para justificar seu spoiling vingativo: "Porque sou um típico brasileiro que, quando vítima de algo, vitimiza alguém idem” (homem, 16 anos).

O que podemos verificar é que nesta categoria, o spoiler excede a narrativa. Neste caso, não é visto apenas como um paratexto da produção ficcional. Não se trata apenas de experiências relacionadas às narrativas contemporâneas e a textualidade na era digital, mas a um conjunto de práticas e dinâmicas sociais, nas quais a informação é central para as disputas em torno do conhecimento subcultural.

\section{Considerações finais}

Este trabalho buscou lançar luz sobre o fenômeno do spoiling em comunidades de fãs de séries americanas no Brasil. A pesquisa concluiu que dentre as múltiplas motivações para o spoiling entre os fãs existiriam práticas que podem se configurar como Não tóxicas e Práticas tóxicas. Observamos que o spoiling como uma prática de comunicação interpessoal, baseada na troca de conhecimento e intencionalidade, pode proporcionar disputas sociais e culturais quando a posse do conhecimento é mais do que apenas um meio para ganhar prestígio entre os colegas, podendo ser usado como uma moeda de barganha nas relações sociais. 
Corrobora-se trabalhos que indicam o uso do spoilier como um capital simbólico de distinção em negociações dentro dos fandoms, ao mesmo tempo em que a categoria de Práticas tóxicas se revela como verdadeiro achado empírico em nossa análise. Embora representem apenas 23,37\% (n = 184) da amostra analisada, as práticas tóxicas demonstram o uso do spoiling como uma forma de diversão por parte do espectador brasileiro, que se aproveita do fato de que apenas um número limitado de pessoas tem acesso à televisão a cabo e usa spoilers como forma de se distinguir em fandoms. Ao mesmo tempo, esses espectadores usam os spoilers como um mecanismo social de punição e de vingança nas relações interpessoais dos fãs que podem ser utilizados por motivos relacionados ou não às produções televisivas.

Novamente, é importante ressaltar que o spoiling também é uma manifestação de fenômenos sociais e culturais que podem refletir o comportamento cultural vinculado à dinâmica social estabelecida pela prática. Entendemos que os spoilers são sensíveis ao contexto e podem ser subjugados a uma manifestação cultural do comportamento brasileiro, a zoeira. Do mesmo modo, é também um capital social ligado à posse do conhecimento, além de ser usado como distinção econômica daqueles que têm acesso à televisão por assinatura no Brasil. Portanto, é importante reforçar que a literatura sobre spoilers não deve generalizar comportamentos on-line sem considerar a complexidade de cada contexto cultural, especialmente quando a questão da distribuição e do acesso ao conteúdo difere dos países que produzem esses programas de TV.

Observa-se, ainda, que dentre as práticas não tóxicas o spoiling demonstrou o potencial positivo do paratexto nas relações interpessoais dos espectadores dentro das comunidades de fãs em que eles trocam informações e se motivam mutuamente a continuarem consumindo séries. Evidentemente, é necessário ressaltar que a metodologia aqui aplicada precisa ser validada em outros procedimentos que forneçam um subsídio mais robusto para compreender a fundo as motivações dos espectadores na produção de spoilers, visto que apesar do anonimato do 
survey, a aplicação deste método pode não compreender sentimentos mais complexos que não seriam verbalizados por meio de uma enquete. Compreendendo o spoiling como um fenômeno cultural e social, estudos adicionais também são necessários para ver se os espectadores de outros países compartilham as mesmas motivações para revelarem spoilers como os brasileiros revelaram neste artigo.

A possibilidade de haver prazer no processo do spoiling reestrutura a nossa compreensão dessas práticas, bem como nos permite pensar sobre o capital cultural dos spoilers como profundamente variável e sensível ao contexto, indicando novas questões e perspectivas para além das já evidenciadas nas pesquisas levantadas neste trabalho.

\section{Referências}

AMARAL, A.; SOUZA, R. V.; MONTEIRO, C. "De westeros no \#vemprarua à shippagem do beijo gay na TV brasileira”. Ativismo de fãs: conceitos, resistências e práticas na cultura digital. Galáxia, n. 29, p. 141-154, 2015.

BAYM, N. Tune in, log on: soaps, fandom, and online community. London: Sage, 2000. BAKHTIN, M. M. Rabelais and his world. Indiana University Press, 1984.

BARDIN, L. Análise de Conteúdo. São Paulo, Edições 70, 2011.

BOURDIEU, P. La distinction: critique sociale du jugement. Paris: Minuit, 1979. What makes a social class? On the theoretical and practical existence of groups. Berkeley Journal of Sociology, n. 32, p. 1-49, 1987.

25, 1989.

Social space and symbolic power. Sociological theory, v. 7, n. 1, p. 14-

BROWN, M. E. Soap opera and women's talk: The pleasure of resistance. London: Sage Publications, 1994.

CAMPANELLA, B. O fã na cultura da divergência: hierarquia e disputa em uma comunidade on-line. Contemporânea, v. 10, n. 3, p. 474-489, 2012.

CASTELLANO, M; MEIMARIDIS, M; DOS SANTOS, M. A. Game of Spoilers: Disputas no consumo da ficção seriada televisiva. Comunicação Midiática, v. 12, n.3, p. 113-128, 2017.

CASTRO, G. G. S. Entretenimento, sociabilidade e consumo nas redes sociais: cativando o consumidor-fã. Fronteiras - estudos midiáticos, v. 14, n. 2, p. 133-140, 2012. 
FECHINE, Y. Transmidiação e cultura participativa: pensando as práticas textuais de agenciamento dos fãs de telenovelas brasileiras. Revista Contracampo, n. 31, p. 5-22, 2015.

GRAY, J. Show sold separately: Promos, spoilers, and other media paratexts. NYU Press, 2010.

GRAY, J; MITTELL, J. 'Speculation on Spoilers: Lost Fandom, Narrative Consumption and Rethinking Textuality'. Participations Journal of audience and reception studies, v. 4, n. 1, p. 1-35, 2007.

HASSOUN, D. Sequential outliers: The role of spoilers in comic book reading. In: Journal of Graphic Novels and Comics, v. 4, n. 2, p. 346-358, 2013.

HILLS, M. Psychoanalysis and digital fandom: Theorizing spoilers and fans' self-narratives. In: LIND, R. A. (Org.). Produsing theory in a digital world: the intersection of audiences and production in contemporary theory. New York: Peter Lang Inc., 2012. p. 105-122.

JENKINS, H. Fans, Bloggers, and Gamers: exploring participatory culture. New York: New York University Press, 2006a.

JENKINS, H. “Do You Enjoy Making the Rest of Us Feel Stupid?”: alt. tv. twinpeaks, the Trickster Author, and Viewer Mastery. Full of secrets: Critical approaches to Twin Peaks. NYU Press, 2006b.

. Cultura da convergência: a colisão entre os velhos e novos meios de comunicação. São Paulo: Aleph, 2009.

JOHNSON, B. K; ROSENBAUM, J. E. Spoiler alert: Consequences of narrative spoilers for dimensions of enjoyment, appreciation, and transportation. Communication Research,v. 42, n. 8, p. 1068-1088, 2014.

LOPES, M. I. V.; GÓMEZ, G. O. (Re)Invenção de gêneros e formatos da ficção televisiva: anuário Obitel 2016. Porto Alegre: Sulina, 2016.

MONTARDO, S. Consumo digital e teoria de prática. Revista Famecos, v. 23, n. 2, p. 1-15, 2016.

NEWMAN, M. Z. Free TV: file-sharing and the value of television. Television 6 New Media, v. 13, n. 6, p. 463-479, 2012.

PASE, A. F; SACCOMORI, C. Significações da prática e do consumo de spoilers de seriados americanos: estragando (ou não) a surpresa da narrativa. In: SÁ, S. P.; CARREIRO, R.; FERRARAZ, R. (Orgs.). Cultura Pop. Salvador: Edufba, 2015. p. 187-209. PERKS, L. G; MCELRATH-HART, N. Spoiler definitions and behaviors in the post-network era. Convergence: The International Journal of Research into New Media Technologies, p. 1-15, 2016a.

RECUERO, R. Redes Sociais na Internet. Porto Alegre: Sulina, 2009.

SULER, J. The online disinhibition effect. Cyberpsychology \& behavior, v. 7, n. 3, p. 321-326, 2004.

THORNTON, S. Club Cultures: Music, Media and Subcultural Capital. Oxford: Polity, 1995. 
WARDE, A. Consumption and Theories of Practice. Journal of Consumer Culture, v. 5 , n. 2, p. 131-153, 2005.

WILLIAMS, R. "It's About Power": Spoilers and Fan Hierarchy in On-Line Buffy Fandom. Slayage: The Online International Journal of Buffy Studies, v. 1 1, p. 1-15, 2004.

\section{Sobre os autores}

Melina Meimaridis - Doutoranda do Programa de Pós-graduação em Comunicação da Universidade Federal Fluminense. Desde 2012, coordena o Série Clube, projeto acadêmico e colaborativo dedicado à investigação e ao debate de aspectos relativos à linguagem da ficção seriada televisiva. Atualmente, desenvolve pesquisas acadêmicas relativas à ficção seriada televisiva, cultura fã, spoilers e Netflix.

Thaiane Oliveira - Doutora em Comunicação Social e professora do Programa de Pós-graduação em Comunicação da Universidade Federal Fluminense. Coordenadora do Fórum de Editores de Periódicos Científicos, da Pró-reitoria de Pesquisa e Inovação, da Universidade Federal Fluminense (FEPC-Proppi/ $\mathrm{UFF})$.

Data de submissão: 04/02/2018

Data de aceite: 17/08/2018 